\title{
An In-Corporate Converter Using Isolation Transformer for Sustainable Energy Resource Applications
}

\author{
Mr. M. Murali, P. Sundramoorthy, Dr. Venugopal N. \\ Dept. of EEE, Kuppam Engineering College
}

\begin{abstract}
This paper proposes a novel converter topology that interfaces four power ports: two sources, one bidirectional storage port, and one isolated load port. The proposed four-port dc/dc converter is derived by simply adding two switches and two diodes to the traditional half-bridge topology. Zero-voltage switching is realized for all four main switches. Three of the four ports can be tightly regulated by adjusting their independent duty-cycle values, while the fourth port is left unregulated to maintain the power balance for the system. Circuit analysis and design considerations are presented; the dynamic modeling and close-loop design guidance are given as well. Experimental results verify the proposed topology and confirm its ability to achieve tight independent control over three powerprocessing paths. This topology promises significant savings in component count and losses for renewable energy power-harvesting systems.
\end{abstract}

Index Terms: DC-DC converter, half-bridge, multiple-input single-output (MISO), multiport, zero-voltage switching (ZVS).

\section{INTRODUCTION}

As $S$ INTEREST in renewable energy systems with various sources becomes greater than before, there is a supreme need for integrated power converters that are capable of interfacing, and concurrently, controlling several power terminals with low cost and compact structure. Meanwhile, due to the intermittent nature of renewable sources, a battery backup is normally required when the ac mains is not available.

This paper proposes a new four-port-integrated $\mathrm{dc} / \mathrm{dc}$ topology, which is suitable for various renewable energy harvesting applications. An application interfacing hybrid photovoltaic (PV) and wind sources, one bidirectional battery port, and an isolated output port is given as a design example. It can achieve maximum power-point tracking (MPPT) for both PV and wind power simultaneously or individually, while maintaining a regulated output voltage.

Compared to the effort spent on the traditional two-port converter, less work has been done on the multiport converter [1]-[27]. But, due to the advantages like low cost and com- pact structure, multiport converters are reported to be designed for various applications, such as achieving three bus voltages of $14 \mathrm{~V} / 42 \mathrm{~V} / \mathrm{H}$.V. (high voltage of around $500 \mathrm{~V}$ )in electric vehicles or hybrid electric vehicles [8], [9], interfacing the PV panel and a battery to a regulated $28-\mathrm{V}$ bus in satellite platform power systems [19], [20], PV energy harvesting with ac mains [4] or the battery backup [6], hybrid fuel cell and battery systems [11],[15], and hybrid ultra capacitor and battery systems [12]. From the topology point of view, multiinput converters based on buck, boost, and buck-boost topologies have been reported in [1]-[7].
The main limitation of these configurations is the lack of a bidirectional port $o$ interface storage device. Multiport converters are also constructed out of a multilinking transformer based on half-bridge or full bridge topologies [8]-[17]. They can meet isolation requirement and also have bidirectional capabilities. However, the major problem is that they use too many active switches, in addition to the bulky transformer, which cannot jus- tify the unique features of low component count and compact structure for the integrated multiport converter.

The proposed four-port dc/dc converter has bidirectional capability and also has one isolated output. Its main components are only four main switches, two diodes, one transformer, and one inductor. Moreover, zero-voltage switching (ZVS) can be achieved for all main switches to allow higher efficiency at higher switching frequency, which will lead to more compact design of this multiport converter. The control design is also investigated based on the modeling of this modified half-bridge topology. In addition, a decoupling network is introduced to al- low the separate controller design for each power port. Finally,

a prototype has been built to verify the four-port converter's circuit operation and control capability. The proposed converter is

a valuable candidate for low-power renewable energy harvesting applications.

\section{TOPOLOGY AND CIRCUIT ANALYSIS}

The four-port topology is derived based on the traditional two- port half-bridge converter, which consists of two main switches $S_{1}$ and $S_{2}$. As shown in Fig. 1, one 
more input power port can be obtained by adding a diode $D_{3}$ and an active switch $S_{3}$. Another bidirectional power path can be formed by adding a freewheeling branch across the transformer primary side, consisting of a diode $D_{4}$ and an active switch $S_{4}$. As a result, the topology ends up with four active switches and two diodes, plus the transformer and the rectification circuit. The proposed converter topology is suitable for a number of power-harvesting applications, and this paper will target the hybrid PV wind application. It should be noted that since the wind turbine normally generates a three- phase ac power, an ac/dc rectifier needs to be installed before this four-port dc/dc interface and after the wind turbine output. And the rectification stage can utilize either active power factor correction (PFC) or passive PFC. However, the ac/dc solution is beyond the scope of this paper

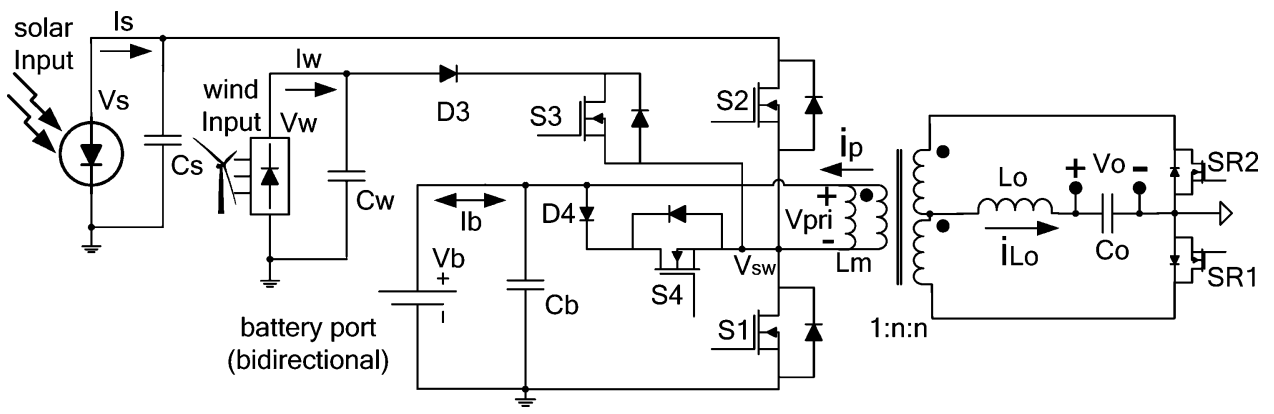

Fig. 1. Four-port half-bridge converter topology, which can achieve ZVS for all four main switches $(S 1, S 2, S 3$, and $S 4$ ) and adopts synchronous rectification for the secondary side to minimize conduction loss.

TABLE I. VALUES OF CIRCUIT PARAMETERS

\begin{tabular}{l|l|l|l|l|l}
\hline output inductor & Lo & $45 \mu \mathrm{H}$ & solar port filter capacitor & Cs & $100 \mu \mathrm{F}$ \\
\hline magnetizing inductor & Lm & $45 \mu \mathrm{H}$ & battery port filter capacitor & Cb & $330 \mu \mathrm{F}$ \\
\hline output filter capacitor & Co & $330 \mu \mathrm{F}$ & wind port filter capacitor & $\mathrm{C}_{\mathrm{w}}$ & $100 \mu \mathrm{F}$ \\
\hline
\end{tabular}

As shown in Fig. 1, the derived four-port-modified half-bridge converter provides three independent control variables, namely duty cycles $d_{1}, d_{2}$, and $d_{3}$ to control $S_{1}, S_{2}$, and $S_{3}$, respectively, while $S_{4}$ will be controlled by $1-d_{1}-d_{2}$ $-d 3$. This allows tight control over three of the converter ports, while the fourth port provides the power balance in the system. The switching sequence ensures a clamping path for the energy of the leakage inductance of the transformer. This energy is further utilized to achieve ZVS for all primary switches for a wide range of source and load conditions. The secondary side adopts a synchronous rectifier to minimize the conduction loss. This also simplifies the feedback controller design, because the transition from continuous conduction mode (CCM) to discontinuous conduction mode (DCM) is avoided.

The values of circuit parameters used in the simulation and experimental circuit are listed in the following table (see Table I).

\section{A. Driving Scheme}

Fig. 2 illustrates a possible modulation approach to realize the constant frequency pulse width modulation (PWM) control, where $V_{\text {Saw }}$ to o th is the saw tooth carrier waveform for modulation, $V_{\mathbf{c} 1}, V_{\mathbf{c} 2}$, and $V_{\mathbf{c} 3}$ are control voltages derived from the volt- age or current feedback controllers. By modulating these control voltages, driving signals for $S_{1}, S_{2}$, and $S_{3}$ can be generated, respectively. Then, by reversing $S_{1}$ and $S_{3}$ driving signals, $S_{4}$ and two SR signals can be obtained. It should be noted that $S_{2}, S_{3}$, and $S_{4}$ do not need to be gated ON at the same time; instead, $S_{3}$ is only required to turn $\mathrm{ON}$ a little earlier before $S_{2}$ turns OFF, and $S_{4}$ is only required to turn ON a little earlier before $S_{3}$ turns OFF. No dead time is necessary between $S_{2}$ and $S_{3}$, nor between $S_{3}$ and $S_{4}$, because the existence of diodes can prevent shoot-through problems. But the dead time between $S_{1}$ and $S_{2}$ and between $S_{1}$ and $S_{4}$ is necessary to prevent shoot-through, and also to create ZVS conditions for $S_{1}$ and $S_{2}$. 
IOSR Journal of Engineering

May. 2012, Vol. 2(5) pp: 1133-1146

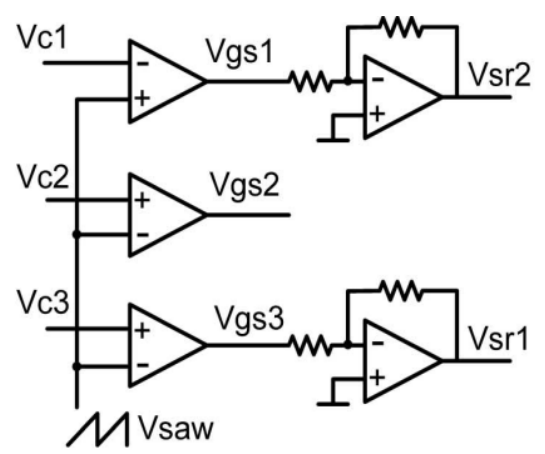

(a)

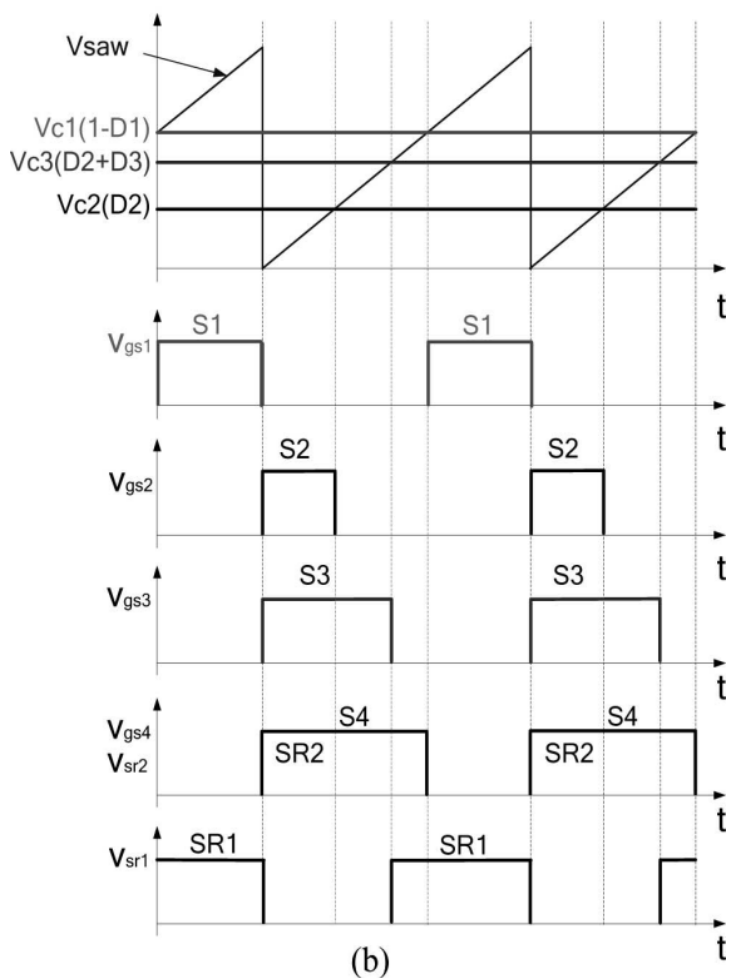

Fig. 2. Proposed modulation scheme. (a) PWM modulation circuits. (b) Driving signal key waveforms.

\section{B. Principle of Circuit Operation}

The steady-state waveforms of the four-port converter are shown in Fig. 3, and the various operation stages in one switch- ing cycle are shown in Fig. 4. To simplify the analysis of 
IOSR Journal of Engineering

May. 2012, Vol. 2(5) pp: 1133-1146

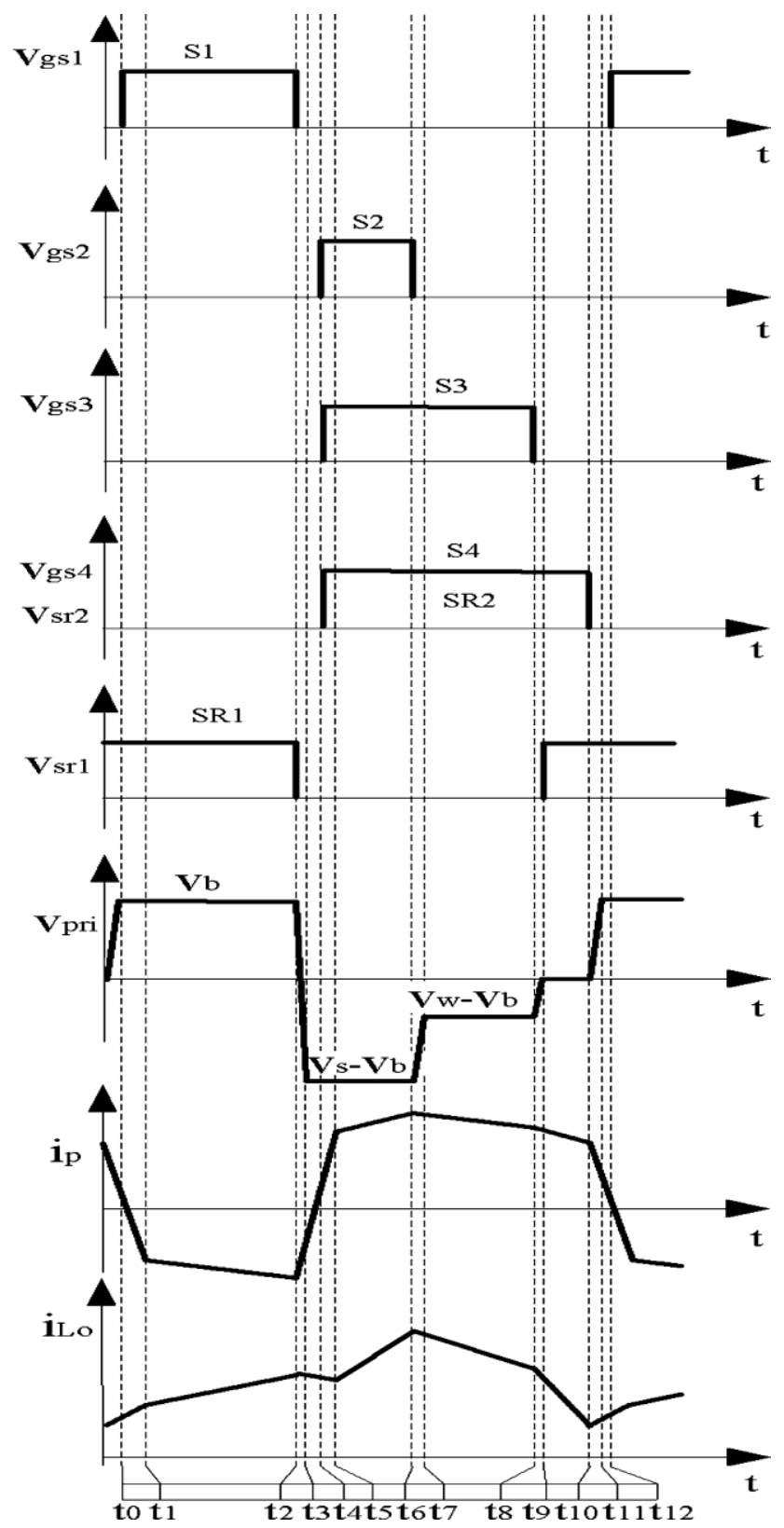

Fig. 3. Steady-state waveforms of the four-port half-bridge converter

Operation, components are considered ideal, except otherwise indicated. The main operation stages are described as follows.

Stage $1(t 0-t 1)$ : Before this stage begins, the body diode of

$S 1$ is forced on to recycle the energy stored in the transformer leakage inductor, and the output is freewheeling. At time $t 0$, $S 1$ is gated ON with ZVS, and then, the leakage inductor is reset to zero and reverse-charged.

Stage $2(t 1-t 2)$ : At time $t 1$, the transformer primary current increases to the reflected current of $i L o$, the body diode of SR2 becomes blocked, and the converter starts to deliver power to output.

Stage 3 (t2-t3): At time $t 2, S 1$ is gated OFF, causing the leakage current ip to charge the $S 1$ parasitic capacitor and discharge the $S 2, \mathrm{~S} 3$, and $S 4$ parasitic capacitors. 
IOSR Journal of Engineering

May. 2012, Vol. 2(5) pp: 1133-1146

Stage 4 (t3-t4): At time $t 3$, the voltage across the $S 2$ parasitic capacitor is discharged to zero, and the $S 2$ body diode conducts to carry the current, which provides the ZVS condition for $S 2$.

During this interval, the output is freewheeling through SR1 and SR2 body diodes.

Stage 5 (t4-t5): At time $t 4, S 2$ is gated ON with ZVS, and then, the leakage inductor is reset to zero and reverse-charged.

The output inductor current drop from $t 2$ to $t 5$ is due to the leakage inductor discharge/charge.

Stage 6 (t5-t6): At time $t 5$, the transformer primary current increases to the reflected current of $i L o$, the body diode of SR1 is blocked, and the converter starts to deliver power to output.

Stage $7(t 6-t 7)$ : At time $t 6, S 2$ is gated OFF, thus causing the leakage current ip to charge the $S 2$ parasitic capacitor and discharge the $S 1$ and $D 3$ parasitic capacitors.

Stage $8(t 7-t 8)$ : At time $t 7$, the voltage across $D 3$ is discharged to zero, and then, $D 3$ conducts. $S 3$ is gated ON before this time; therefore, $S 3$ has natural ZVS. Output inductor current freewheels through SR2 during this period.

Stage $9(t 8-t 9)$ : At time $t 8, S 3$ is gated OFF, thus causing the leakage current ip to charge $S 2$ and $S 3$ parasitic capacitors and discharge $S 1$ and $D 4$ parasitic capacitors.

Stage 10 (t9-t10): At time $t 9$, the voltage across $D 4$ is discharged to zero and $D 4$ conducts. Since $S 4$ is gated ON before this time, the leakage current freewheels through $D 4$ and $S 4$,so that the leakage energy is trapped. On the secondary side, output inductor current freewheels through SR1 and SR2 .

Stage 11 (t10-t11): At time $t 10, S 4$ is gated OFF, causing the

trapped leakage energy to discharge the $S 1$ parasitic capacitor and charge the $S 2, S 3$ and $S 4$ parasitic capacitors.

Stage 12 (t11-t12): At time $t 11$, the voltage across $S 1$ is discharged to zero, and the $S 1$ body diode conducts to carry the current, which provides ZVS condition for $S 1$. During this interval, the output is freewheeling. This is the end of the switching cycle.

\section{Steady-State Analysis}

Assuming an ideal converter, the steady-state voltage governing relations between different port voltages can be determined by equating the voltage-second product across the converter's two main inductors to zero. First, using volt-second balance across the primary transformer magnetizing inductance $L M$ in $C C M$, we have $V b D 1=(V s-V b) D 2+(V w-V b) D 3$. (1) 
IOSR Journal of Engineering

May. 2012, Vol. 2(5) pp: 1133-1146
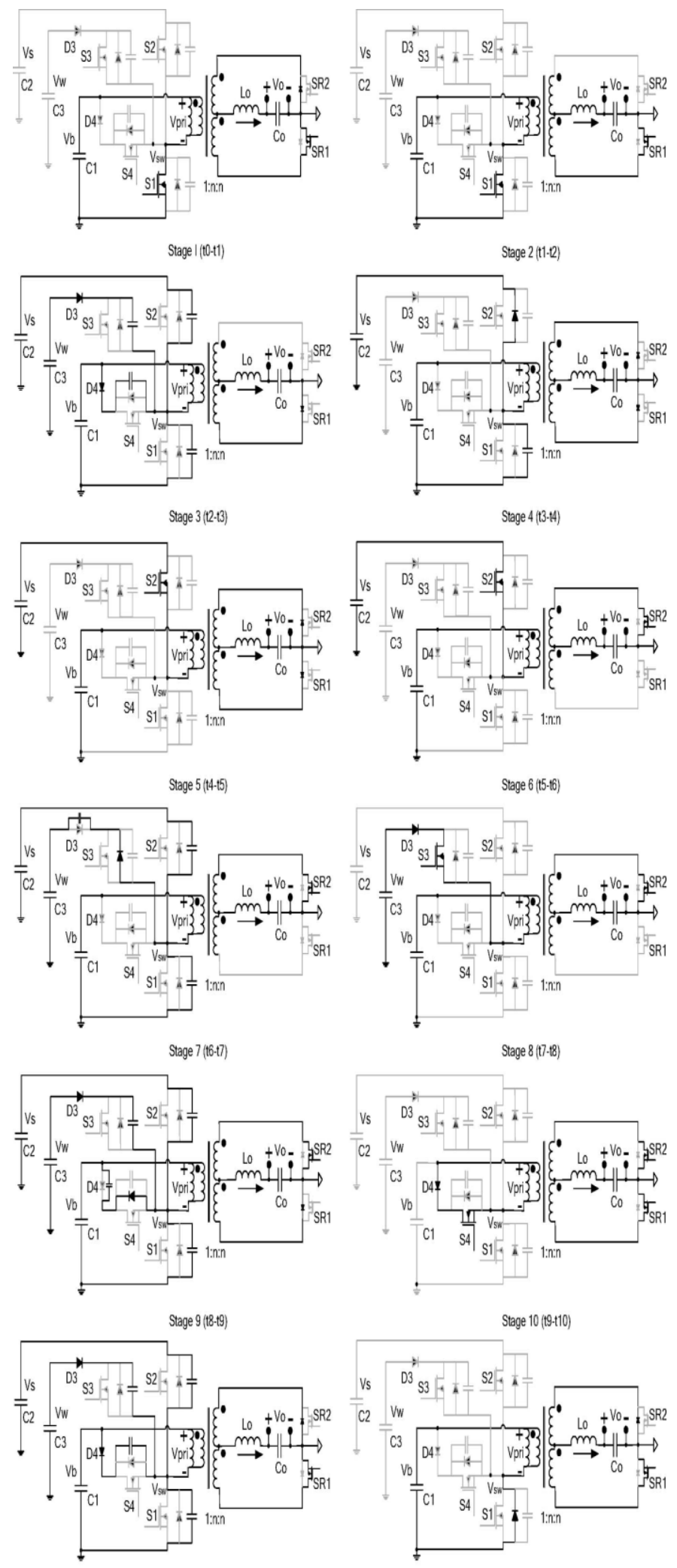

Stage 11 (t10-t11)

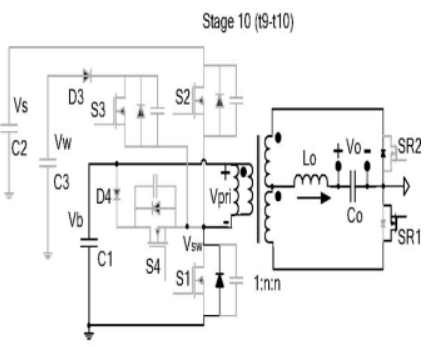

Stage 12 (111-112)

Fig. 4. Operation stages of the four-port half-bridge converter. 
IOSR Journal of Engineering

May. 2012, Vol. 2(5) pp: 1133-1146

Assuming CCM operation, the voltage-second balance across

the load filter inductor $L o$ then yields $V b D 1+(V s-V b) D 2+(V w-V b) D 3=\operatorname{Von}(2)$ where $n$ is the turns ratio of the transformer, $V s, V w, V b, V o$ are the solar input, wind input, battery, and output voltages, respectively. The following equation is based on the power balance principle, by assuming a lossless converter, steady-state port currents can be related as follows:

$V s I s+V w I w=V b I b+V o I o(3)$

where $I s, I w, I b, I o$ are the average solar input, wind input,

battery bidirectional, and load currents, respectively. The battery current $I b$ is positive during charging and negative during discharging.

\section{ZVS Analysis}

ZVS of the switches $S 1$ and $S 2$ can be realized through the

energy stored in the transformer leakage inductor, while ZVS of $S 3$ and $S 4$ is always maintained, because the proposed driving scheme ensures that paralleling diodes of $S 3$ and $S 4$ will be forced on before the two switches turn ON. After $S 4$ is turned OFF, the leakage energy is released to discharge the $S 1$ parasitic capacitor and charge $S 2, S 3$, and $S 4$ 's parasitic capacitors, to create the ZVS condition of $S 1$. And the following condition should be satisfied:

$1 / 2 L k(I M+n I o) 2>2 \operatorname{Coss} V 2 b+\operatorname{Coss} V s V b+C \operatorname{coss} V w V b, I M+n I o>0$ (4) where $L k$ is the transformer leakage inductance, MOSFET parasitic capacitances of $S 1, S 2, S 3$ and $S 4$ are assumed to be equal as Coss, and $I M$ is the average transformer magnetizing current, which satisfies:

$I b=D 1(I M-n I o)+D 2(I M+n I o)+D 3(I M+n I o) \cdot(5)$

Rearranging (5), we can obtain $I M$ as follows:

$I M=I b+(D 1-D 2-D 3)$ nIo $D 1+D 2+D 3$. (6)

After $S 1$ is turned OFF, the leakage energy will charge the

$S 1$ parasitic capacitor and discharge $S 2, S 3$, and $S 4$ 's parasitic capacitors to achieve ZVS for $S 2$

$1 / 2 L k(I M-n I o) 2>\operatorname{Coss} V 2 s+1 / 2 \operatorname{Coss} V 2 w+1 / 2 \operatorname{Coss} V 2 b, I M-n I o<0$. (7)

According to (7), when the load current $I o$ is small and the

transformer magnetizing current $I M$ is large, $I M-n I o<0$

cannot be met. In other words, ZVS of $S 2$ will be lost.

However, in most load/source conditions, ZVS of $S 2$ is achievable. It should be noted that ZVS of $S 3$ and $S 4$ can be naturally achieved if the voltage relation $V b<V w<V s$ is satisfied to ensure that the paralleling diodes will always be forced on before these switches turn ON. On one hand, $V w<V s$ is not difficult to meet since the solar port and wind port can be reversed if the wind port voltage $V w$ is larger than the solar port voltage $V s$. Even if $V w$ is not always lower than $V s$ in the whole voltage ranges, the converter itself still works, but may lose some conduction period for the $S 2$ branch depending on the driving overlap of $S 2$ and $S 3$. The solution is to change the driving scheme to avoid the $S 2$ and $S 3$ overlap. On the other hand, it is a step-down conversion from PV or wind port to battery port; therefore, the battery voltage $V b$ will be always lower than the PV voltage $V s$ and the wind source voltage $V w$.

To sum up, ZVS of all main switches can be achieved to maintain higher efficiency when the converter is operated at higher switching frequency, because of the potential savings in Switching losses.

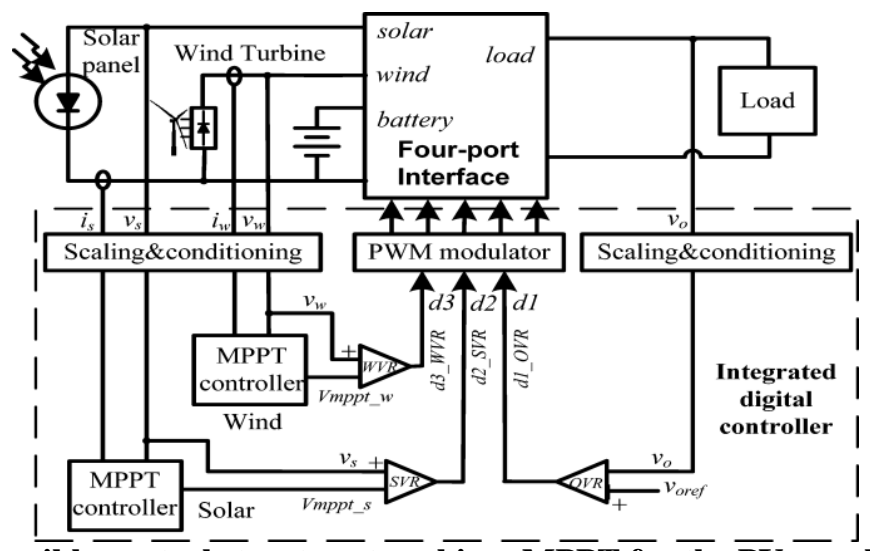

Fig. 5. Possible control structure to achieve $\overline{\mathrm{MPPT}} \overline{\bar{P}} \overline{\mathrm{for}} \overline{\mathrm{Ph}} \overline{\mathrm{PV}} \overline{\text { panel and the }}$ 
IOSR Journal of Engineering

May. 2012, Vol. 2(5) pp: 1133-1146

Wind turbine, meanwhile maintaining output voltage regulation. OVR, SVR, and WVR loops are to control $d 1, d 2$, and $d 3$, respectively.

The WVR loop is taking a very similar structure to SVR, except that its voltage reference represents the optimal operating voltage of the rectified wind turbine output voltage. The WVR loop is made to control $d 3$. This control strategy allows the load voltage to be tightly regulated while maximizing the PV and wind power harvesting. In this system, the battery storage plays the significant role of balancing the system energy by injecting power at heavy loads and absorbing excess power when available PV and wind power exceeds the load demand.

\section{B. Dynamic Modeling}

In order to design the SVR, WVR, and OVR controllers, a

small signal model of the four-port converter is desired. The detailed modeling procedure can refer to [19], which is proposed for a three-port converter. And for this four-port converter, the general modeling procedure is very similar to [19].

Therefore, to avoid unnecessary repetition, only a brief introduction is given here. First, state-space equations for five energy storage elements during the four main circuit stages are developed. For the aforementioned mode of operation, these include the solar side capacitor $C s$, the wind-side capacitor $C w$, the transformer magnetizing inductor $L M$, the output inductor $L o$, and the output capacitor $C o$. In the next step, state-space equations in the four main circuit stages (corresponding to the turn $\mathrm{ON}$ of four main switches) will be averaged, and then applied with the small signal perturbation. Finally, the first-order small-signal perturbation components will be collected to form the matrices A and B, which actually represent the converter power stage model. It should be noted that the symbolic derivation of these transfer functions is fairly tedious. Alternatively, the dynamics of the plant can be calculated by computer software like MATLAB. The resultant state-space averaging model takes the following form:

$d^{\wedge} x(t) d t=A^{\wedge} x(t)+B^{\wedge} u(t), \wedge(t)=I^{\wedge} x(t)$

With matrices $A$ and $B$, transfer functions for PV, wind and output voltages to different duty-cycle values can be extracted according to (10). For example, $G(s)(5,1)$ represents the fifth state variable $v o$ and the first control variable $d 1$, thus equals to open-loop transfer function of $v o(s) / d 1(s)$. Therefore, the row number denotes the sequence of state variable, and the column number denotes that of control input

$G=(s I-A)-1 B$

$g 11=G(s)(5,1), g 21=G(s)(1,1), g 31=G(s)(2,1)$

$g 12=G(s)(5,2), g 22=G(s)(1,2), g 32=G(s)(2,2)$

$g 13=G(s)(5,3), g 23=G(s)(1,3), g 33=G(s)(2,3)$.

Fig. 6 illustrates the small signal model diagram when closing SVR, WVR, and OVR loops, which consists of the converter model and the feedback controllers. FM represents the PWM modulator gain and different $\mathrm{Kv}$ values represent different voltage signal sensing gains, which can be treated as the fixed proportional values.

As can be seen from Fig. 6, the three control loops are coupled with each other, which make it difficult to design close-loop Compensators for each control loop. Therefore, a decoupling network, as shadowed in Fig. 6, is introduced, so that the controlloops can be designed independently with different control-loop bandwidth requirement. Since output-port voltage regulation requirement is the most stringent of the three and the PV panel and wind turbine characteristics are relatively slower, the SVR loop is designed to have a one-decade lower bandwidth than that of OVR. Moreover, WVR bandwidth can be set to be lower than that of SVR to further reduce SVR and WVR loop interactions, since the mechanical behavior of wind blades is slower than the PV behavior of PV panels.

The derivation of decoupling network $G *$ is described as follows.

The state vector matrix $X$ can be written $\operatorname{as} X=G \cdot U *$,

where $U *$ is the modified input vector made up of duty cycles

$U, U *=G * \cdot U$.

Therefore, $X=G \cdot G * \cdot U$. According to modern control theory, our goal is to make $G \cdot G *$ a diagonal matrix to allow one control input to determine one output independently. 
Therefore, based on $G^{*}=G^{-1} \cdot X \cdot U-1$, It should be noted that the decoupling network is only intended to calculate and derive the separate control objects, while it does not need to be implemented in the real controller design.In other word, the decoupling can be taken as one part of the control objects, but not included in the compensators. Now, the cross-coupled three-loop control system is decoupled into three independent single-loop subsystems. The system can then be controlled using independent loop controllers and each compensator can be designed separately as well. For example, the OVR controller can then be designed based on the plant transfer function

Fig. 6. Small signal model diagram, control inputs and outputs are decoupled to enable separate controller design. The far right signals are routed to the far left ones in this diagram. Vsref, $V w$ ref, and $V o$ ref are the references for solar, wind and output voltages, respectively.HSVR ,HWVR, andHOVR are the compensators need to be designed

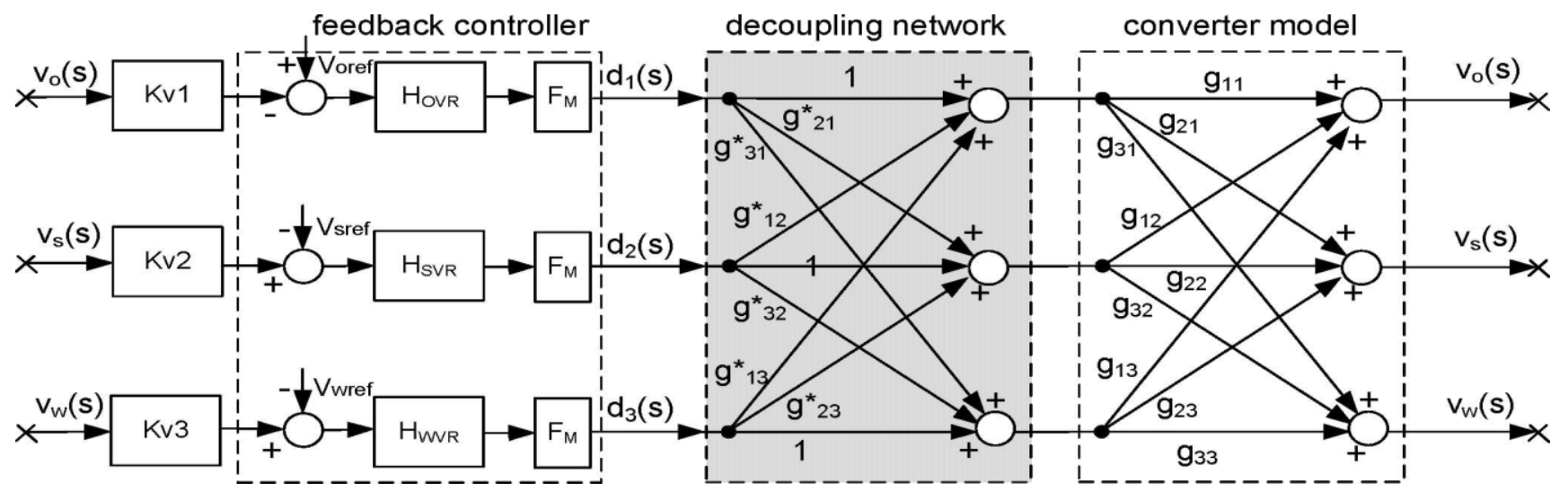

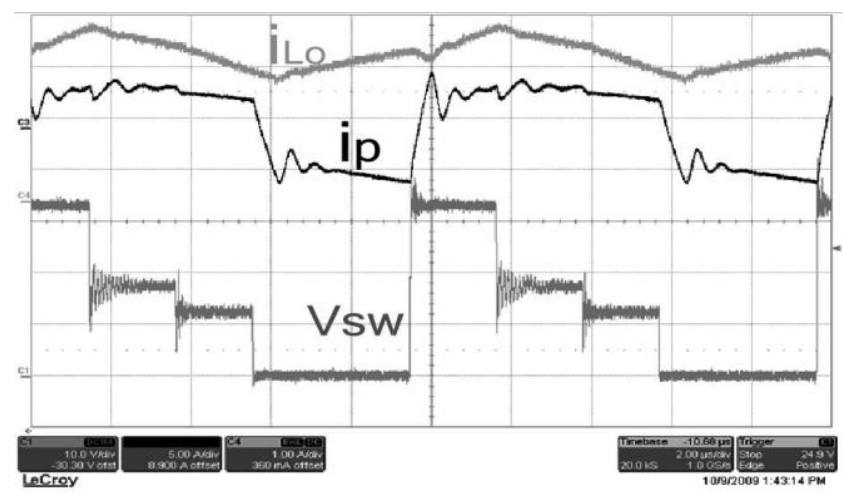

(a)

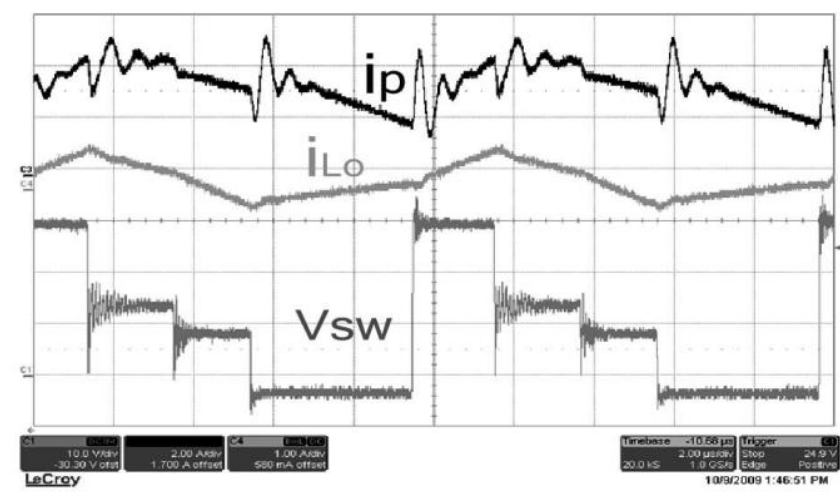

(b)

Fig. 7. Steady-state waveforms. (a) Loading the output port when the battery current is zero. (b) Loading the battery port when the output current is zero. 
IOSR Journal of Engineering

May. 2012, Vol. 2(5) pp: 1133-1146

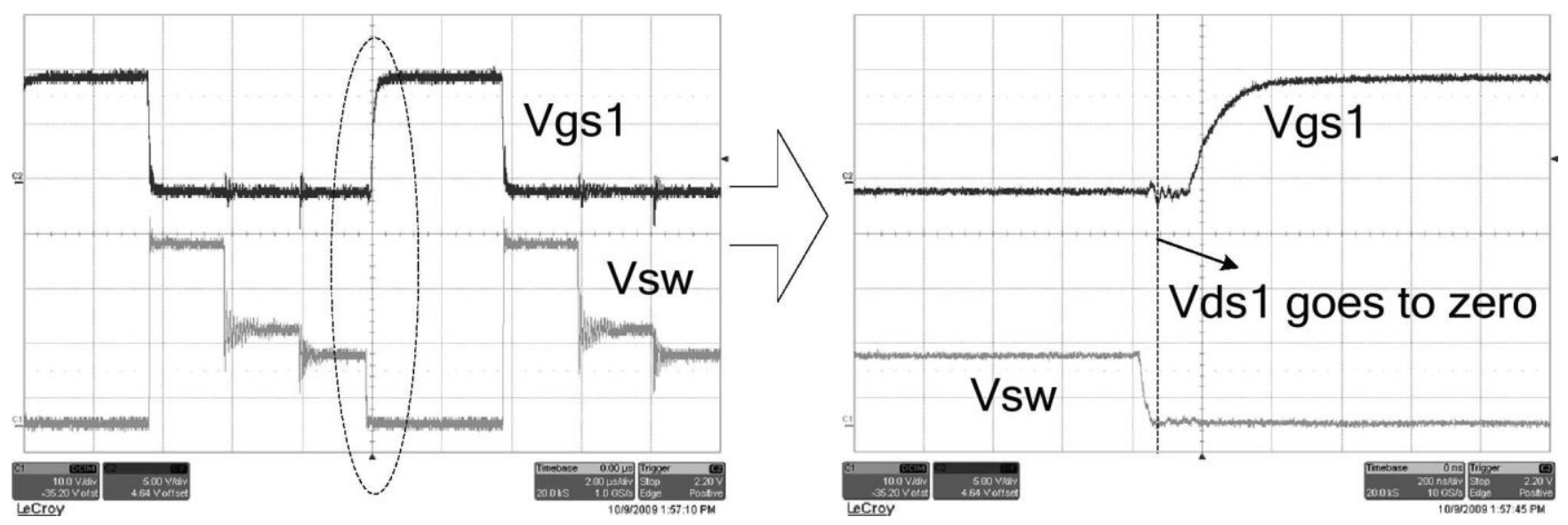

Fig. 8. Vgs and $V$ sw of the switch $S 1$.

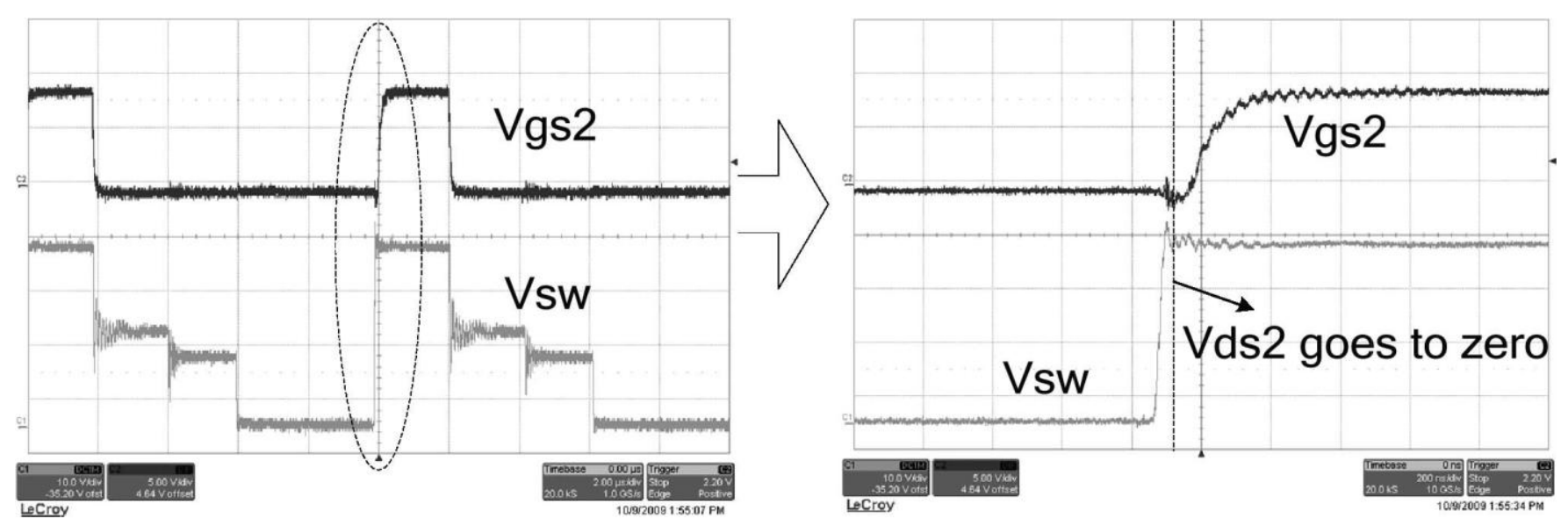

Fig. 9. Vgs and $V$ sw of the switch $S 2$.

TABLE II

DIFFERENT LOAD/SOURCE CURRENT LEVEL CONDITIONS

\begin{tabular}{c|c|c|c}
\hline \multirow{2}{*}{} & \multicolumn{3}{|c}{ Load/Source Current Level Conditions (\%) } \\
\cline { 2 - 4 } & $\mathrm{V}_{\mathrm{s}}=35.6 \mathrm{~V}$ & $\mathrm{~V}_{\mathrm{w}}=28.2 \mathrm{~V}$ & $\mathrm{~V}_{\mathrm{o}}=12 \mathrm{~V}$ \\
\hline Case1 & 10 & 10 & 90 \\
\hline Case2 & 90 & 10 & 90 \\
\hline Case3 & 10 & 90 & 90 \\
\hline Case4 & 90 & 90 & 90 \\
\hline Case5 & 90 & 10 & 10 \\
\hline Case6 & 10 & 90 & 10 \\
\hline Case7 & 90 & 90 & 10 \\
\hline Case8 & 10 & 10 & 10 \\
\hline
\end{tabular}


IOSR Journal of Engineering

May. 2012, Vol. 2(5) pp: 1133-1146

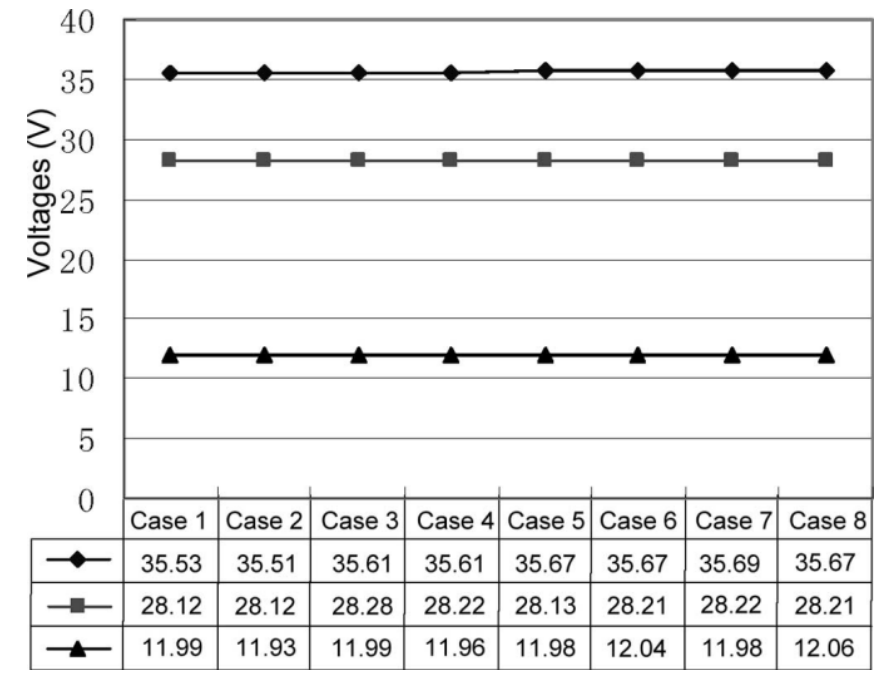

Fig. 10. Solar port, wind port, and output port voltages under different load/ source conditions

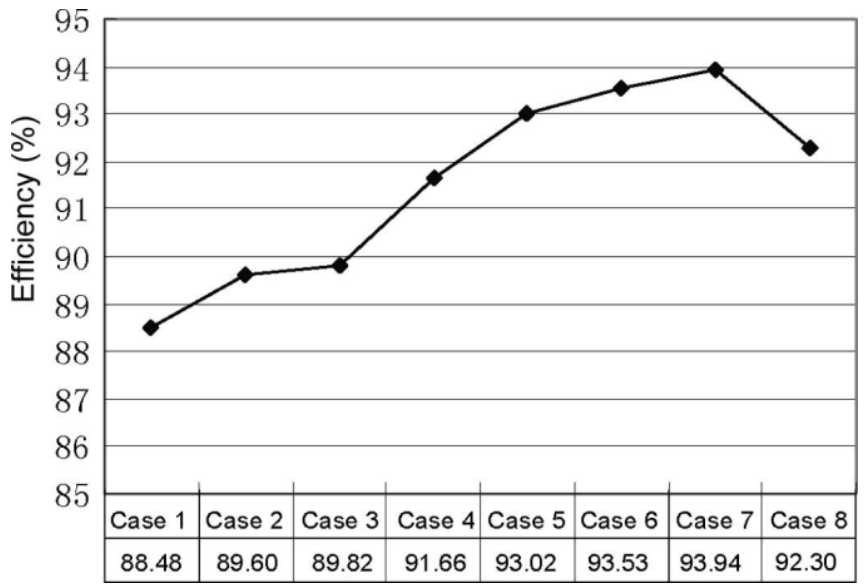

Fig. 11. Efficiency under different load/source conditions.

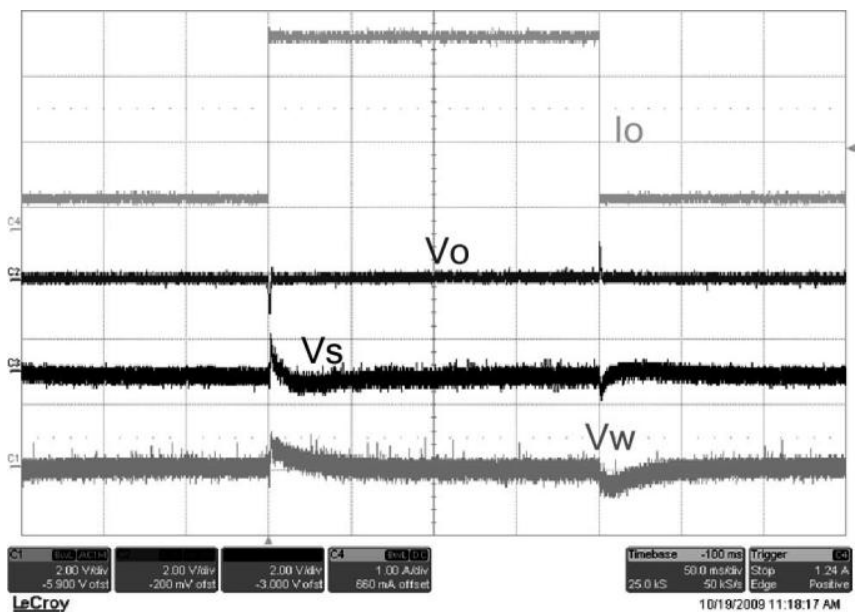

Fig. 12. Transient response of solar, wind, and output voltages when the load is perturbed by a step change between $10 \%$ and $90 \%$ rated output current. 

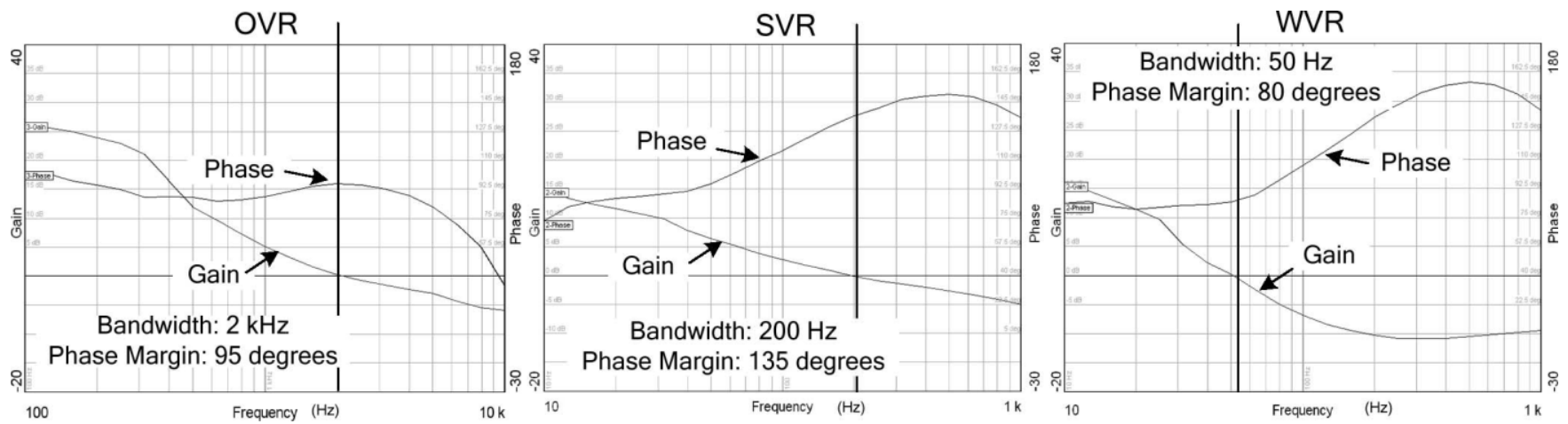

Fig. 13. Bode plots testing results for OVR, SVR, and WVR, respectively. OVR bandwidth is set to be ten times of that of SVR, and SVR bandwidth is four times of that of WVR.

The open-loop OVR-loop bode plot implies that it has two main poles at around $L o C o$ resonance, which causes a $-40 \mathrm{~dB} /$ decade slope for gain plot while not having enough phase margin. This double pole characteristic is because that this topology is buck-type derived in terms of the output port.

Therefore, the design objective is to make the gain plot pass $0 \mathrm{~dB}$ line at $-20 \mathrm{~dB} / \mathrm{dec}$ de slope while maintaining a sufficient phase margin. A tradition PID controller is recommended to boost the phase. The PID compensator of HOVR takes the following form:

$H \mathrm{OVR}=80(s / 2 \pi 400+1)(s / 2 \pi 500+1) / s(s / 2 \pi 4000+1)(s / 2 \pi 5000+1)$

Similarly, SVR and WVR controllers can also be designed once their decoupled plant transfer functions are derived. The SVR and WVR bode plots before compensation have very high bandwidth. But the control bandwidth should be reduced to minimize loop interaction, SVR compensator HSVR is then designed to enforce relatively low control-loop bandwidth with some phase boost. Therefore. a PID controller with very low gain is adopted to achieve this design goal. And WVR compensator HWVR is set at even lower gain to have a lower bandwidth than SVR loop. HSVR and HWVR are designed as follows:

$H S V R=0.08(s / 2 \pi 20+1)(s / 2 \pi 30+1) / s(s / 2 \pi 1000+1)(s / 2 \pi 2000+1)$

$H \mathrm{WVR}=0.02(s / 2 \pi 20+1)(s / 2 \pi 30+1) / s(s / 2 \pi 1000+1)(s / 2 \pi 1500+1)$

\section{EXPERIMENTAL RESULTS}

A four-port dc/dc converter prototype is built to verify the

circuit operation. The circuit parameters are: solar port, 30

$40 \mathrm{~V} / 1.5 \mathrm{~A}$; wind port, $20-30 \mathrm{~V} / 1.5 \mathrm{~A}$; battery port, $12-$

$18 \mathrm{~V} / 3 \mathrm{~A}$; and output port, $12 \mathrm{~V} / 3.3 \mathrm{~A}$. The switching frequency is $100 \mathrm{kHz}$, and it is implemented by the digital control to achieve the close-loop regulation.

Fig. 7 gives the steady-state waveforms when loading the output port (a) and loading the battery port (b). The switch-node voltage $V$ sw shows a four-stage wave shape, corresponding to the turn $\mathrm{ON}$ of four main switches with four different voltage levels. In addition, there is no CCM and DCM transition for the output inductor current $i L o$,

which avoids the sharp change of plant dynamic characteristics and simplifies the output-voltage feedback-controller design. The transformer magnetizing current ip is determined by both the reflected output current and the battery current. Figs. 8 and 9 show the gating signal Vgs and switching node Vsw waveforms of the switches $S 1$ and $S 2$. Since $S 3$ and $S 4$ have ZVS under all conditions, as mentioned earlier, only $S 1$ and $S 2$ waveforms are presented here. The conclusion is that all four main switches can achieve ZVS, because they all turn ON after their $V$ ds go to zero.

Table II shows eight different load and source combinations with each one of them to be either $10 \%$ or $90 \%$ load/source 
IOSR Journal of Engineering

May. 2012, Vol. 2(5) pp: 1133-1146

condition, while the battery port provides the power balance. The test setup is realized by connecting the solar port and wind port of the converter to two independent PV array simulators instead of the solar panel and the wind turbine. Then, two different $I-V$ curves are assigned for the solar and wind port, and the DSP code is tuned so that the SVR and WVR voltage references are at $10 \%$ or $90 \%$ rated current point. As a result, two sources will have four different combinations. A battery is connected to sink the excess power or source the deficit power, and the load is set to sink either $10 \%$ or $90 \%$ rated output current. Therefore, there are eight different conditions for one load and two sources, as described in Table II.

Fig. 10 depicts all three-port voltages under different load/source conditions. The cross regulation of $V s, V w$, and $V o$ are $0.5 \%, 0.6 \%$ and $1.1 \%$, respectively. This confirms its capability to regulate three of the four ports tightly.

Fig. 11 shows the efficiency curve under different load/source conditions, as shown in Table II. The highest efficiency is 93.9\% when most of the power is exchanged within the primary side from the solar and wind port to the battery port; the reason is that this operation has minimal transformer losses.

\section{CONCLUSION}

This paper has presented a novel $\mathrm{dc} / \mathrm{dc}$ converter topology capable of interfacing four dc power ports: two input source ports, a bidirectional storage port, and a galvanic-ally isolated loading port. The converter features low component count and ZVS operation for all primary switches. Modification based on the traditional half-bridge topology makes it convenient for the practicing engineers to follow the power stage design. Three degrees of freedom necessary to control power flow in the system are provided by a four-stage constant-frequency switching sequence. This four-port converter is suitable for renewable energy systems, where the energy storage is required while allowing tight load regulation.

It is suitable for low-power applications since based on the half-bridge topology, while the multiport converter based on the full-bridge topology maybe suitable for high-power applications. For the hybrid PV wind system, the proposed control structure is able to achieve maximum power harvesting for PV and/or wind power sources, meanwhile maintaining a regulated output voltage. The close-loop controller design is investigated based on the dynamic modeling of the converter power stage. Proper decoupling method is introduced to help

\section{REFERENCES}

[1] Y. Liu and Y. M. Chen, "A systematic approach to synthesizing multiinput DC-DC converters," IEEE Trans. Power Electron., vol. 24, no. 2, pp. 116-127, Jan. 2009.

[2] B. G. Dobbs and P. L. Chapman, "A multiple-input DC-DC converter topology," in Proc. IEEE Power Electron. Lett., Mar, 2003, vol. 1, pp. 6-9.

[3] N. D. Benavides and P. L. Chapman, "Power budgeting of a multipleinput buck-boost converter," IEEE Trans. Power Electron., vol. 20, no. 6, pp. 1303-1309, Nov. 2005.

[4] H. Matsuo,W. Lin, F. Kurokawa, T. Shigemizu, and N.Watanabe, "Characteristics of the multiple-input DC-DC converter," IEEE Trans. Ind. Appl., vol. 51, no. 3, pp. 625-631, Jun. 2004.

[5] A. Khaligh, J. Cao, and Y. Lee, "A multiple-input DC-DC converter topology," IEEE Trans. Power Electron., vol. 24, no. 3, pp. 862-868, Mar. 2009.

[6] Y. M. Chen, Y. C. Liu, and F. Y. Wu, "Multi-input DC/DC converter based on the multiwinding transformer for renewable energy applications," IEEE Trans. Ind. Appl., vol. 38, no. 4, pp. 1096-1104, Aug. 2002.

[7] A. Kwasinski, "Identification of feasible topologies formultiple-input DCDC converters," IEEE Trans. Power Electron., vol. 24, no. 3, pp. 856-861, Mar. 2009.

[8] G. Su and L. Tang, "A reduced-part, triple-voltage DC-DC converter for EV/HEV power management," IEEE Trans. Power Electron., vol. 24, no. 10, pp. 2406-2410, Oct. 2009.

[9] F. Z. Peng, H. Li, G. J. Su, and J. S. Lawler, "A new ZVS bidirectional DC-DC converter for fuel cell and battery applications," IEEE Trans. Power Electron., vol. 19, no. 1, pp. 54-65, Jan. 2004.

[10] H. Tao, J. L. Duarte, andM. A.M. Hendrix, "Three-port triple-half-bridge bidirectional converter with zero-voltage switching," IEEE Trans. Power Electron., vol. 23, no. 2, pp. 782-792, Mar. 2008.

[11] W. Jiang and B. Fahimi, "Multi-port power electric interface for renewable energy sources," in Proc. IEEE Appl. Power Electron. Conf., 2009, pp. 347-352.

[12] D. Liu and H. Li, "A ZVS bi-directional DC-DC converter for multiple energy storage elements," IEEE Trans. Power Electron., vol. 21, no. 5, pp. 1513-1517, Sep. 2006.

[13] C. Zhao, S.D.Round, and J.W.Kolar, "An isolated three-port bidirectional DC-DC converter with decoupled power flow management,” IEEE Trans. Power Electron., vol. 21, no. 5, pp. 2443-2453, Sep. 2008. 
IOSR Journal of Engineering

May. 2012, Vol. 2(5) pp: 1133-1146

[14] H. Tao, A.Kotsopoulos, J. L.Duarte, andM.A.M.Hendrix, "Transformercoupled multiport ZVS bidirectional DC-DC converter with wide input range," IEEE Trans. Power Electron., vol. 23, pp. 771-781, Mar. 2008.

[15] J. L. Duarte, M. Hendrix, and M. G. Simoes, "Three-port bidirectional converter for hybrid fuel cell systems," IEEE Trans. Power Electron., vol. 22, no. 2, pp. 480-487, Mar. 2007.

[16] H. Al-Atrash and I. Batarseh, "Boost-integrated phase-shift full-bridge converters for three-port interface," in Proc. IEEE Power Electron. Spec.Conf., 2007, pp. 2313-2321.

[17] H. Tao, A. Kotsopoulos, J. L. Duarte, and M. A. M. Hendrix, "Family of multiport bidirectionalDC-DC converters," in Proc. IEEE Power Electron. Spec. Conf., 2008, pp. 796-801.

[18] H. Al-Atrash, F. Tian, and I. Batarseh, "Tri-modal half-bridge converter topology for three-port interface," IEEE Trans. Power Electron., vol. 22, no. 1, pp. 341-345, Jan. 2007.

[19] Z. Qian, O. Abdel-Rahman, J. Reese, H. Al-Atrash, and I. Batarseh, "Dynamic analysis of three-port DC/DC converter for space applications," in Proc. IEEE Appl. Power Electron. Conf., 2009, pp. 28-34.

[20] Z. Qian, O. Abdel-Rahman, M. Pepper, and I. Batarseh, "Analysis and design for paralleled three-portDC/DC converterswith democratic current sharing control," in Proc. IEEE Energy Convers. Congr. Expo., 2009, pp. 13751382.

[21] H. Mao, J. Abu-Qahouq, S. Luo, and I. Batarseh, "Zero-voltage-switching half-bridge DC-DC converter with modified PWMcontrolmethod,” IEEE Trans. Power Electron., vol. 19, no. 4, pp. 947-958, Jul. 2004.

[22] H. Tao, A. Kotsopoulos, J. L. Duarte, and M. A. M. Hendrix, "Multiinput bidirectional DC-DC converter combining DC-link and magneticcoupling for fuel cell systems," in Proc. IEEE Ind. Appl. Conf., 2005, pp. 2021-2028.

[23] R. W. Erickson and D. Maksimovic, Fundamentals of Power Electronics, 2nd ed. Boston, MA: Kluwer, 2000, ch. 7.

[24] H. Al-Atrash, M. Pepper, and I. Batarseh, "A zero-voltage switching three-port isolated full-bridge converter," in Proc. IEEE Int. Telecommun. Energy Conf., 2006, pp. 411-418.

[25] Z. Qian, O. Abdel-Rahman, H. Hu, and I. Batarseh, "Multi-channel threeport DC/DC converters as maximal power tracker, battery charger and bus regulator," in Proc. IEEE Appl. Power Electron. Conf., 2010, pp. 2073-2079.

[26] H. Krishnaswami and N. Mohan, "Three-port series-resonant DC-DC converter to interface renewable energy sources with bidirectional load and energy storage ports," IEEE Trans. Power Electron., vol. 24, no. 9-10, pp. 2289-2297, Oct. 2009.

[27] Z. Qian, O. Abdel-Rahman, H. Al-trash, and I. Batarseh, "Modeling and control of three-port DC/DC converter interface for satellite applications, IEEE Trans. Power Electron., vol. 25, no. 3, pp. 637-649, Mar. 2010.

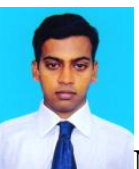

\section{Authors}

M. Murali has obtained his B.E. (Electrical and Electronics Engineering) from Anna University, Chennai in 2010. $\mathrm{He}$ is completed his M.Tech. (Power Electronics) from JNTU Anantapur. He is editor of International journal of Emerging Technology and Advanced Engineering. His research area of interest includes Power Electronics and Embedded Systems.

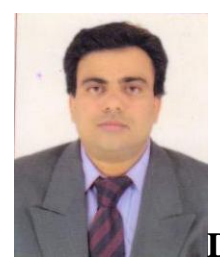

Dr.Venugopal.N has obtained his B.E. degree from Bangalore University and M.E. Degree from Bangalore University respectively. He has 16 years of teaching experience. He is research scholar from Dr. MGR University, Chennai. His research area is improvement of Digital Image Processing \& Video separation. Currently working as an HOD of EEE department \& Director, R \& D in Kuppam Engineering College, Kuppam, Chittoor Dist. Andhra Pradesh. His research area of interest includes Power electronics and Embedded Systems.

P.Sundra moorthy has obtained his B.E.\&M.E degree from Anna University, Chennai. Respectively. He has 6 years of teaching experience. His research area of interest includes Power Electronics and Instrumentation. 